\title{
Individual and combined (Plus-hybrid) effect of cytoplasmic male sterility and xenia on maize grain yield
}

\author{
Sofija Bozinovic ${ }^{*}$, Slaven Prodanovic ${ }^{2}$, Jelena Vancetovic $^{1}$, Ana Nikolic ${ }^{1}$, Danijela Ristic ${ }^{1}$, \\ Marija Kostadinovic ${ }^{1}$, and Dragana Ignjatovic ${ }^{1}$
}

\begin{abstract}
Plus-hybrid effect refers to a combined effect of cytoplasmic male sterility (CMS) and xenia in maize (Zea mays L.) It could be used in commercial production by growing a mixture of $80 \%$ CMS hybrid and $20 \%$ of another fertile hybrid. The aim of this research was to examine individual and combined CMS and xenia effects on two hybrids widely grown in Serbia. Sterile and fertile versions of ZP 1 and ZP 2 hybrids (three-way; Iodent $\times$ Lancaster dents) were used as females, while ZP 1, ZP 2, ZP 3, ZP 4, and ZP 5 (three-way or single cross; Iodent (BSSS) $\times$ Lancaster dents) were used as pollinators. All of them belong to medium maturity group. The trial was set up at one location in Serbia (Zemun Polje) in 2009, 2010, and 2011. Molecular analysis of the five genotypes was done using simple sequence repeat (SSR) primers. Plus-hybrid effect on grain yield ranged from $-6.2 \%$ to $6.2 \%$; on thousand kernel weight from $-1.7 \%$ to $5.2 \%$; on number of kernels per area from $-1.0 \%$ to $8.0 \%$. The poor response could be due to a use of three-way instead of single cross hybrids in $\mathrm{S}$ type of sterility. Modified Rogers' distance between hybrids was in the range 0.211 to 0.378 and was not relevant for the effect, which depended mostly on the sterile hybrid genotype and the fertile hybrid pollinator ability. This approach should be more suitable for female hybrids with slightly poorer performance, already being produced on a sterile base.
\end{abstract}

Key words: Cytoplasmic male sterility, plus-hybrid effect, xenia, Zea mays.

\section{INTRODUCTION}

Cytoplasmic male sterility (CMS) refers to the maternally inherited failure to produce or release functional pollen; it has been widely used in maize (Zea mays L.) hybrid seed production for its cost effectiveness (Havey, 2004). There are three types of CMS in maize, CMS-T (Texas), CMS-S (USDA), and CMS-C (Charrua), differentiated by the reaction to nuclear fertility restorer genes, mitochondrial DNA restriction digest patterns, and complements of low molecular weight plasmids (Sofi et al., 2007). If a single cross hybrid were to be produced on a CMS base, the female (seed) parent inbred line should be recessive homozygous for nuclear fertility restorer genes with a male-sterile cytoplasm. The male (pollen) parent inbred line should be a dominant homozygous for nuclear restorer genes with fertile (normal) or sterile cytoplasm. This cross would result in a heterozygous single cross $F_{1}$ generation, which, when planted in the field, would be pollen-fertile.

${ }^{1}$ Maize Research Institute Zemun Polje, Research and Development Department, 11185, Belgrade, Serbia.

"Corresponding author (sbozinovic@mrizp.rs).

${ }^{2}$ University of Belgrade, Faculty of Agriculture, 11080, Belgrade, Serbia.

Received: 4 April 2014.

Accepted: 3 January 2015

doi: $10.4067 /$ S0718-58392015000200004
Only CMS-S and CMS-C are being commercially used today, because of susceptibility of CMS-T to Southern Corn Leaf Blight disease (Laughnan and GabayLaughnan, 1983). Sterile hybrids have somewhat higher grain yield (GY) than their fertile counterparts, mostly due to the increase in kernel number per square meter (KNM) (Weingartner et al., 2002a; 2002b; Kaeser et al., 2003b; Munsch, 2008). This can be explained by the fact that, since there is no pollen production, great amounts of nutrients and energy necessary to form pollen have been targeted to the grain formation. Also, some authors have shown that CMS-T and CMS-C type of sterility increase GY more than CMS-S type, but not significantly (Kaeser, 2003a; Munsch, 2008).

Xenia refers to the immediate effect of foreign pollen on non-maternal kernel tissues, and it is especially important in plants with highly developed endosperm, like maize. In the maize kernel, half of the genome of the embryo and one third of the genome of the endosperm is derived from the pollen. This means that all the traits related to the embryo and endosperm could potentially be modified by the pollen parent. The conventional cultivation of single cross hybrids leads to a pronounced inbreeding depression because kernels produced in the $\mathrm{F}_{1}$ generation plants are actually $\mathrm{F}_{2}$ generation. Cross-fertilization with another hybrid increases grain heterozygosity, what probably affects the grain yield increase. Many authors 
showed xenia effect on the kernel and embryo weight that leads to the increased GY (Bulant and Gallais, 1998; Weingartner et al., 2002a; 2002b; Munsch, 2008; Liu et al., 2010). Xenia effect has already being used in TopCross maize production system for production of high oil corn (Thomison et al., 2002; 2003). It involves planting a mixture of $90 \%$ high yielding sterile hybrid and $10 \%$ special high-oil pollinator that benefits to higher oil content in mother hybrid kernel.

Plus-hybrid effect is the combined effect of cytoplasmic male sterility (CMS) and xenia in maize (Weingartner et al., 2002a; 2002b). Implementation of the effect in commercial maize production is based on the idea to grow a mixture consisting of $80 \%$ of a sterile hybrid as the female and $20 \%$ of another fertile hybrid as the pollinator. In this way positive effects of CMS and xenia on grain yield and grain quality could be easily used. This approach is suitable for the breeding programs that implement CMS in maize hybrid seed production. In contrast to conventional hybrid seed production, male parental line must not carry restorer genes for used type of sterility in order to get $F_{1}$ sterile hybrid that will be used as a female component in Plus-hybrid system. Several researchers determined positive Plus-hybrid effect on the most important traits in maize (Weingartner et al., 2002a; 2002b; 2004; Munsch, 2008). Preliminary results of Weingartner et al. (2002a) revealed that Plus-hybrid effect on GY over different locations and years was on average $9 \%$. In addition, for the maximum grain yield to be obtained hybrids in Plus-hybrid mixture must flower synchronously. Some authors pointed out that the highest kernel set is obtained when pollination occurred 3 to $8 \mathrm{~d}$ after the first silks emerge (Kaeser et al., 2003b; Anderson et al., 2004).

Xenia effect is related to the genetic distance between the genotypes and cross-fertilization with another hybrid increases grain heterozygosity, which probably affects the GY increase (Bulant and Gallais, 1998; Bulant et al., 2000). On the other hand, Munsch (2008) did not reveal relationship between genetic distance of hybrids in Plushybrid combination and xenia effect on GY and thousand kernel weight (TKW). Reif et al. (2005) concluded that modified Rogers' distance (MRD) (Wright, 1978) is the most appropriate for the prediction of heterosis with genetic distances.

The aim of the research presented herein was to determine individual, as well as combined (Plus-hybrid) effect of CMS and xenia on the grain yield. We wanted to test this novel system on different genotypes that are widely grown in Serbia, and in different environment than in previous studies. Additional goal was to examine the importance of genetic distance between hybrids for the expression of this effect. The results could provide additional information on Plus-hybrid effect in maize and the possibility of its use in maize production for food and feed.

\section{MATERIALS AND METHODS}

\section{Plant material and experimental design}

Sterile (st) and fertile versions of maize hybrids $\mathrm{ZP} 1$ and ZP 2 were used as females, while ZP 1, ZP 2, ZP 3 , $\mathrm{ZP} 4$, and ZP 5 hybrids were used as pollinators. These genotypes were chosen for the experiment because they belong to the medium maturity group. Early to medium hybrids are of greater interest nowadays since they escape drought, which has become the major limiting factor for maize grain yield. Also, ZP 1 and ZP 2 were already available in both sterile and fertile versions. CMS versions of ZP 1 and ZP 2 hybrids had S type of sterility, while all the fertile hybrids had normal $(\mathrm{N})$ cytoplasm. All hybrids were three-way crosses, except ZP 4, which was a single cross. Early to medium maturity hybrids grown in Serbia are usually three-way cross so we wanted to examine these effects on this type of germplasm. Detailed data on the studied hybrids have been summarized in Table 1.

The trial was carried out at one location in Zemun Polje (4451'53" N, 20¹8'36" E), Serbia, in 3 yr (2009, 2010, and 2011). Sowing was carried out mechanically on 26 April 2009, 6 May 2010, and 22 April 2011. The type of soil was leached chernozem. The following rates of fertilizers were applied in autumn: $90 \mathrm{~kg} \mathrm{~N} \mathrm{ha}^{-1}, 90 \mathrm{~kg}$ $\mathrm{P} \mathrm{ha}^{-1}$, and $90 \mathrm{~kg} \mathrm{~K} \mathrm{ha}^{-1}$. A total amount of $69 \mathrm{~kg} \mathrm{~N} \mathrm{ha}^{-1}$ in the form of urea was applied to the soil in spring during the seedbed preparation. Standard cropping practices were applied to keep the disease-free plots during vegetation. Harvesting was done manually at physiological maturity. Meteorological data during growing season are presented in Table 2.

Field trial was set up according to the randomized complete block (RCB) split plot experimental design. There were four main plots (blocks), each for one female hybrid genotype. The main plots consisted of five subplots in three replicates representing five pollinator hybrids.

Table 1. Hybrid characteristics and their use in a Plus-hybrid combination.

\begin{tabular}{llcccc}
\hline Hybrid & Hybrid type & Genetic background & $\begin{array}{c}\text { FAO maturity } \\
\text { group }\end{array}$ & Kernel type & $\begin{array}{c}\text { Plus-hybrid } \\
\text { component }\end{array}$ \\
\hline ZP 1 & Three-way & Iodent $\times$ Lancaster & 300 & Dent & CMS-S/N \\
ZP2 & Three-way & Iodent $\times$ Lancaster & 300 & Dent & CMS-S/N \\
ZP3 & Three-way & Iodent $\times$ Lancaster & 300 & Dent & Female/pollinator \\
ZP4 & Single cross & BSSS $\times$ Iodent & 300 & Dent & P \\
ZP5 & Three-way & BSSS $\times$ Lancaster & 300 & Dent & Pollinator \\
\hline
\end{tabular}

CMS-S: Cytoplasmic male sterility in S type; N: normal (fertile) cytoplasm. 
Table 2. Precipitation sum and average monthly temperatures during maize growing season in 2009, 2010, and 2011 in Zemun Polje.

\begin{tabular}{|c|c|c|c|c|c|c|}
\hline \multirow[b]{2}{*}{ Month } & \multicolumn{3}{|c|}{ Precipitation } & \multicolumn{3}{|c|}{ Average temperature } \\
\hline & 2009 & 2010 & 2011 & 2009 & 2010 & 2011 \\
\hline & \multicolumn{3}{|c|}{$\mathrm{mm} \longrightarrow$} & \multicolumn{3}{|c|}{${ }^{\circ} \mathrm{C}$} \\
\hline April & 27.3 & 7.3 & 44.0 & 13.8 & 15.8 & 13.2 \\
\hline May & 39.7 & 27.4 & 64.1 & 19.3 & 19.9 & 17.5 \\
\hline June & 36.3 & 71.9 & 167.3 & 23.0 & 21.0 & 21.0 \\
\hline July & 46.2 & 31.2 & 35.6 & 23.7 & 24.1 & 23.2 \\
\hline August & 19.7 & 36.6 & 68.2 & 24.0 & 24.1 & 23.1 \\
\hline September & 54.4 & 4.0 & 68.0 & 17.0 & 20.6 & 17.6 \\
\hline Sum/Average & 223.6 & 178.4 & 447.2 & 20.1 & 20.9 & 19.3 \\
\hline
\end{tabular}

Each subplot consisted of 14 rows $18 \mathrm{~m}$ long and 0.75 $\mathrm{m}$ apart. The plant density was 66600 plants ha ${ }^{-1}$. In two middle rows of each subplot of one block the same female hybrid was sown (ZP 1, ZP 2, ZP 1st or ZP 2st), and in six rows left and right the pollinator hybrid specific for that subplot was sown. In this way the female hybrid was completely surrounded with one pollinator. The female rows were $3.7 \mathrm{~m}$ apart from top and bottom end of a subplot with a total of 100 plants. Fertile female hybrids were manually detasseled prior to pollen shedding.

\section{Analyzed traits and statistical analysis}

Anthesis-silking interval (ASI) was measured for each subplot, as the difference between days to silking of the female hybrid (50\% plants in a row) and days to anthesis of the pollinator (50\% plants in a row shed pollen). Ears from two middle rows were harvested manually. Samples from 20 plants were taken to determine grain moisture at harvest time, in order to calculate GY $\left(\mathrm{t} \mathrm{ha}^{-1}\right)$ at standard moisture content (14\%). Three samples of 200 kernels were taken from each subplot to determine (TKW) using the formula:

$$
\text { (A - (Mst\% - 14) } \times \mathrm{A} / 100)
$$

where $A$ is average 200 kernel mass and $M s t \%$ is grain water content at the time of the measurement.

Kernel number per square meter was obtained by multiplying average kernel number per ear and number of plants per square meter. Average kernel number per ear for each genotype was calculated by multiplying row number and average kernel number over four randomly chosen rows. Although this calculation is more theoretical than practical we considered it could nevertheless provide us with sufficient comparable information on the studied effects on this trait. The data on number of ears per square meter needed for more correct calculation of KNM was not available.

All field data were analyzed with ANOVA for randomized complete block split-plot experimental design. $T$ tests were used to determine significant differences between the genotypes at the 0.1, 0.05, and 0.01 probability levels.

\section{Estimation of the effects}

The CMS effect for hybrids per se: change in a trait of isogenically pollinated sterile hybrid (pollinated by its fertile counterpart) compared to the same isogenically pollinated fertile hybrid. Values were averaged across the replicates and years for all the traits.

$$
\mathrm{CMS}_{\mathrm{A}}(\%)=\left(\mathrm{HYB}_{\mathrm{stA} \times \mathrm{A}}-\mathrm{HYB}_{\mathrm{ftA} \times \mathrm{A}}\right) / \mathrm{HYB}_{\mathrm{ftA} \text { ×ftA }}
$$

CMS effect for hybrid combinations: change in a trait of non-isogenically pollinated sterile hybrid (pollinated by unrelated genotype) compared to non-isogenically pollinated fertile hybrid pollinated with the same unrelated pollinator.

$$
\mathrm{CMS}_{\mathrm{A} \times \mathrm{B}}(\%)=\left(\mathrm{HYB}_{\mathrm{stA} \times \mathrm{B}} \times \mathrm{HYB}_{\mathrm{ftA} \times \mathrm{B}}\right) / \mathrm{HYB}_{\mathrm{ftA} \times \mathrm{B}}
$$

Xenia effect: change in a trait of non-isogenically pollinated fertile hybrid compared to the same isogenically pollinated fertile hybrid.

$$
\mathrm{XEN}_{\mathrm{A}}(\%)=\left(\mathrm{HYB}_{\mathrm{ftA} \times \mathrm{B}}-\mathrm{HYB}_{\mathrm{ftA} \mathrm{AA}}\right) / \mathrm{HYB}_{\mathrm{ftA} \mathrm{AA}}
$$

Plus-hybrid effect: change in a trait of sterile nonisogenically pollinated hybrid compared to the same fertile isogenically pollinated hybrid.

$$
\operatorname{PHE}_{\mathrm{A}}(\%)=\left(\mathrm{HYB}_{\mathrm{stA} \times \mathrm{B}}-\mathrm{HYB}_{\mathrm{ftA} \times \mathrm{A}}\right) / \mathrm{HYB}_{\mathrm{ftA} \times \mathrm{A}}
$$

\section{Genetic distance analysis}

Simple sequence repeat (SSR) analysis was conducted on bulked samples of 20 plants per genotype. Young leaves were freeze-dried and ground to powder with liquid nitrogen. Genomic DNA was extracted using a mini CTAB method (Williams et al., 1993). Twenty-nine SSR loci from the bnlg/umc/phi set were assayed using the sample of five genotypes. Primers that failed to amplify consistently in all genotypes or with banding patterns difficult to score accurately were excluded from the study. A final set of 21 SSR loci was used for marker analysis of the genotypes (Table 3 ).

\begin{tabular}{|c|c|c|c|}
\hline Primer & Bin & $\mathrm{Nr}$ of fragments & PIC \\
\hline umc 2235 & 1.06 & 5 & 0.692 \\
\hline umc 1013 & 1.08 & 10 & 0.849 \\
\hline bnlg 198 & 2.08 & 6 & 0.772 \\
\hline umc 1526 & 2.08 & 7 & 0.821 \\
\hline bnlg 1350 & 3.08 & 11 & 0.873 \\
\hline umc 1109 & 4.10 & 7 & 0.789 \\
\hline phi 085 & 5.06 & 3 & 0.527 \\
\hline phi 087 & 5.06 & 6 & 0.776 \\
\hline umc 1019 & 5.06 & 7 & 0.748 \\
\hline phi 126 & 6.00 & 3 & 0.407 \\
\hline umc 1006 & 6.02 & 6 & 0.768 \\
\hline bnlg 1443 & 6.05 & 7 & 0.801 \\
\hline umc 1859 & 6.06 & 8 & 0.832 \\
\hline umc 1695 & 7.00 & 10 & 0.864 \\
\hline umc 1015 & 7.03 & 8 & 0.825 \\
\hline umc 1841 & 7.03 & 2 & 0.239 \\
\hline umc 1782 & 7.04 & 9 & 0.856 \\
\hline umc 1040 & 9.01 & 6 & 0.809 \\
\hline umc 1492 & 9.04 & 3 & 0.555 \\
\hline umc 1507 & 10.04 & 5 & 0.689 \\
\hline umc 1827 & 10.04 & 4 & 0.696 \\
\hline$\Sigma$ & & 133 & \\
\hline Average & & 6.3 & 0.723 \\
\hline
\end{tabular}

The amplification reaction was carried out in $25 \mu \mathrm{L}$ reaction volume containing $1 \times$ enzyme buffer, $2.4 \mathrm{mM}$ $\mathrm{MgCl}_{2}, 200 \mu \mathrm{M}$ dNTPs, $0.5 \mu \mathrm{M}$ primers, $1 \times$ BSA, $1 \mathrm{U}$ Taq polymerase and $200 \mathrm{ng}$ DNA. Amplification profiles were 
applied as follows: an initial denaturation at $95{ }^{\circ} \mathrm{C}$ for 5 min, followed by 15 cycles each of denaturation at $95^{\circ} \mathrm{C}$ for $30 \mathrm{~s}$, annealing at $63.5^{\circ} \mathrm{C}$ for $1 \mathrm{~min}\left(-0.5^{\circ} \mathrm{C}\right.$ at each cycle) and extension at $72^{\circ} \mathrm{C}$ for $1 \mathrm{~min}$; another 22 cycles of $95{ }^{\circ} \mathrm{C}$ for $30 \mathrm{~s}, 56{ }^{\circ} \mathrm{C}$ for $1 \mathrm{~min}$, and $72{ }^{\circ} \mathrm{C}$ for $1 \mathrm{~min}$ were performed.

Amplified fragments were separated in 6\% denaturated polyacrylamide gels and stained with silver nitrate. The gels were scanned and SSR profiles for each primer were scored. The probes used detected single loci and each detected band was assumed to be an allele. Allele frequency was scored as percentage of individual bands within the sample. Polymorphism information content (PIC) was calculated according to Lynch and Walsh (1998).

Genetic distances between populations were evaluated by the Modified Rogers Distance defined as:

$$
\text { MRD }=\sqrt{\frac{1}{2 m} \sum_{i=1}^{m} \sum_{j=1}^{a i}\left(p_{i j}-q_{i j}\right)^{2}},
$$

where $p_{i j}$ and $q_{\mathrm{ij}}$ are the frequencies of the $j^{\text {th }}$ allele at the $i^{\text {th }}$ marker in the two entries under consideration, ai is the number of alleles at the $i^{\text {th }}$ marker, and $m$ is the number of markers. The genetic distance matrix according to MRD was submitted for hierarchical cluster analyses of unweighted pair group method using arithmetic mean (UPGMA) and necessary computation were performed using NTSYS-pc2.1 program package (Exeter Software, East Setauket, New York, USA; Rohlf, 2000).

\section{RESULTS}

Anthesis-silking intervals had values from -2.11 (for ZP 1 st $\times \mathrm{ZP} \mathrm{5}$ ) to 4.33 (for ZP $2 \times \mathrm{ZP} 3$ ) (Table 4). In most combinations, anthesis of the pollinator occurred before silking of the female hybrid. Only ZP 1 (both sterile and fertile) silked before ZP 2 and ZP 5 pollinators shed pollen. Pollinator ZP 5 shed pollen last of all pollinator hybrids. ANOVA for ASI showed significant impact of the year, maternal genotype and pollinator, but the type of cytoplasm did not have impact on this trait (Table 5).

ANOVA showed that year and hybrid pollinator, as well as Year $\times$ Female interaction and Year $\times$ Pollinator $\times$ Female interaction had significant impact on GY (Table $5)$. TKW was under influence of the year and pollinator, as well as Year $\times$ Female and Year $\times$ Female $\times$ Cytoplasm type interactions. All the main factors (year, female hybrid, pollinator hybrid, and cytoplasm type) influenced $\mathrm{KNM}$ and most of the interactions for this trait were also

Table 4. Anthesis silking interval (ASI) between female hybrids and pollinator hybrids.

\begin{tabular}{lcrcrr}
\hline & \multicolumn{5}{c}{ Pollinator hybrid } \\
\cline { 2 - 6 } Female hybrid & ZP 1 & ZP 2 & ZP 3 & ZP 4 & ZP 5 \\
\cline { 2 - 6 } ZP 1st & 1.22 & -0.67 & 0.44 & 0.00 & -2.11 \\
ZP 1 & 0.33 & -1.11 & 0.67 & 0.56 & -1.89 \\
ZP 2st & 3.56 & 2.22 & 4.00 & 3.67 & 1.00 \\
ZP 2 & 4.11 & 2.00 & 4.33 & 3.44 & 1.00 \\
\hline
\end{tabular}

Table 5. Mean square of ANOVA for anthesis silking interval (ASI), grain yield (GY), thousand kernel weight (TKW) and kernel number per square meter (KNM).

\begin{tabular}{lccccc}
\hline Source of variation $^{\mathrm{a}}$ & df & ASI & GY & TKW & KNM \\
\hline Year (Y) & 2 & $12.27^{* *}$ & $15.30^{* *}$ & $14320.86^{* * *}$ & $2665893.34^{* * *}$ \\
Female hybrid (F) & 1 & $457.61^{* * *}$ & $0.43 \mathrm{~ns}$ & $15.32 \mathrm{~ns}$ & $2245715.03^{* * *}$ \\
$\mathrm{Y} \times \mathrm{F}$ & 2 & $1.62 \mathrm{~ns}$ & $5.02^{*}$ & $2785.2^{* *}$ & $256617.21^{*}$ \\
Cytoplasm type (C) & 1 & $0.01 \mathrm{~ns}$ & $0.83 \mathrm{~ns}$ & $197.15 \mathrm{~ns}$ & $70355.87^{*}$ \\
$\mathrm{Y} \times \mathrm{C}$ & 2 & $0.27 \mathrm{~ns}$ & $0.06 \mathrm{~ns}$ & $259.56 \mathrm{~ns}$ & $95804.73^{* *}$ \\
$\mathrm{~F} \times \mathrm{C}$ & 1 & $0.27 \mathrm{~ns}$ & $2.02^{\dagger}$ & $19.93 \mathrm{~ns}$ & $107104.18^{*}$ \\
$\mathrm{Y} \times \mathrm{F} \times \mathrm{C}$ & 2 & $5.34^{* * *}$ & $5.74^{* *}$ & $826.63^{*}$ & $7128.19 \mathrm{~ns}$ \\
Pollinator hybrid (P) & 4 & $71.64^{* * *}$ & $2.13^{\dagger}$ & $1416.62^{* * *}$ & $285199.62^{* * *}$ \\
$\mathrm{Y} \times \mathrm{P}$ & 8 & $12.91^{* * *}$ & $1.53 \mathrm{~ns}$ & $615.75^{*}$ & $239607.45^{* * *}$ \\
$\mathrm{~F} \times \mathrm{P}$ & 4 & $0.62 \mathrm{~ns}$ & $1.41 \mathrm{~ns}$ & $122.00 \mathrm{~ns}$ & $23538.86 \mathrm{~ns}$ \\
$\mathrm{CV}, \%$ & & 12.05 & 8.0 & 4.69 & 5.27 \\
\hline${ }^{* * * * * * *}$ Significant & at & the & $0.1,0.05,0.01$, and 0.001 probability levels,
\end{tabular}
respectively.

significant. The rest of the interactions were not significant for any of the traits examined, and therefore they are not presented in the Table 5.

Cytoplasmic male sterility did not have significant impact either on ZP 1st per se or on its combinations with pollinators, except that ZP 1st $\times$ ZP 5 showed decrease $(-3.6 \%, \mathrm{P}<0.1)$ of $\mathrm{KNM}$ in relation to $\mathrm{ZP} 1 \times \mathrm{ZP} 5$ (Table 6). ZP 2st per se had $4.9 \%$ higher yield on average than its fertile analogue $(\mathrm{P}<0.05)$, while $\mathrm{ZP} 2 \mathrm{st} \times \mathrm{ZP} 1$ had higher yield $\left(6.5 \%\right.$ or $\left.0.8 \mathrm{tha}^{-1}\right)$ than $\mathrm{ZP} 2 \times \mathrm{ZP} 1(\mathrm{P}>$ $0.05)$. CMS evidently had higher influence on TKW of ZP 2 per se than ZP 1 per se - ZP 2st had $4.0 \%$ higher TKW than its fertile analogue $(\mathrm{P}<0.1)$. However, $\mathrm{ZP} 2$ st $\times \mathrm{ZP}$ 1 decreased in TKW in relation to ZP $2 \times \mathrm{ZP} 1(-3.4 \%, \mathrm{P}$ $<0.1)$. Only ZP 2st per se had higher KNM than its fertile analogue and the increase was $4.7 \%(\mathrm{P}<0.05)$.

Grain yield of ZP 1 was influenced only by ZP 5 xenia $(\mathrm{P}<0.1)$, but negatively by decrease of $5.4 \%$ (Table 7$)$. Three out of four pollinators had increased ZP $2 \mathrm{GY}$, but this change was not significant. Xenia did not have significant impact on TKW of ZP 1 hybrid, although there was a decrease of about $3.4 \%$ under the influence of ZP 5. However, ZP 1 and $\mathrm{ZP} 3$ raised TKW value of $\mathrm{ZP} 2$ hybrid for $5.4 \%$ (19 g, $\mathrm{P}<0.05)$ i.e. $6.6 \%$ (23 g, P<0.05). ZP 5 influenced KNM of both hybrids, while the rest of the pollinators did not have significant influence on this trait.

Three out of four Plus-hybrid combinations of ZP 1 hybrid had lower GY than its fertile analogues isogenically

Table 6. Cytoplasmic male sterility (CMS) effect on grain yield (GY), thousand kernel weight (TKW), and kernel number per square meter (KNM) for hybrids per se and their crosses with the pollinators.

\begin{tabular}{lcccccc}
\hline Genotype & GY & $\begin{array}{c}\text { CMS } \\
\text { effect }\end{array}$ & TKW & $\begin{array}{c}\text { CMS } \\
\text { effect }\end{array}$ & KNM & $\begin{array}{c}\text { CMS } \\
\text { effect }\end{array}$ \\
\hline ZP 1st $\times$ ZP 1 & 12.87 & -0.4 & 360.99 & -0.1 & 4157.18 & 0.4 \\
ZP 1st $\times$ ZP 2 & 13.20 & 0.6 & 357.14 & -3.3 & 4215.26 & 3.4 \\
ZP 1st $\times$ ZP 3 & 12.61 & 0.0 & 369.47 & 0.7 & 4098.30 & -0.8 \\
ZP 1st $\times$ ZP 4 & 12.66 & -2.4 & 364.53 & 2.5 & 4143.65 & -0.2 \\
ZP 1st $\times$ ZP 5 & 12.12 & -0.8 & 354.61 & 2.3 & 4205.76 & $-3.6^{\dagger}$ \\
\hline ZP 2st $\times$ ZP 2 & 13.14 & $4.9^{*}$ & 364.76 & $4.0^{\dagger}$ & 3994.03 & $4.7^{*}$ \\
ZP 2st $\times$ ZP 1 & 12.99 & 6.5 & 357.08 & -3.4 & 3996.34 & 1.9 \\
ZP 2st $\times$ ZP 3 & 13.31 & 2.8 & 368.95 & -1.3 & 3883.81 & 2.7 \\
ZP 2st $\times$ ZP 4 & 13.12 & 2.0 & 363.44 & 2.1 & 3950.95 & 2.8 \\
ZP 2st $\times$ ZP 5 & 12.44 & -2.3 & 358.77 & 2.8 & 4121.98 & -0.4 \\
\hline
\end{tabular}

†, Significant at the 0.1 and 0.05 probability levels, respectively. 
Table 7. Xenia effect on grain yield (GY), thousand kernel weight (TKW), and kernel number per square meter (KNM) for nonisogenically pollinated fertile hybrids.

\begin{tabular}{lcccccc}
\hline Genotype & GY & $\begin{array}{c}\text { Xenia } \\
\text { effect }\end{array}$ & TKW & $\begin{array}{r}\text { Xenia } \\
\text { effect }\end{array}$ & KNM & $\begin{array}{r}\text { Xenia } \\
\text { effect }\end{array}$ \\
\hline ZP 1 × ZP 2 & 13.12 & 1.6 & 369.60 & 2.3 & 4076.05 & -1.6 \\
ZP 1 × ZP 3 & 12.61 & -2.4 & 367.09 & 1.8 & 4132.30 & -0.2 \\
ZP 1 × ZP 4 & 12.97 & 0.4 & 355.72 & -1.4 & 4153.38 & 0.3 \\
ZP 1 × ZP 5 & 12.22 & $-5.4^{\dagger}$ & 346.72 & -3.4 & 4363.18 & $5.4^{\dagger}$ \\
\hline ZP 2 × ZP 1 & 12.20 & -2.6 & 369.69 & $5.4^{*}$ & 3922.14 & 2.8 \\
ZP 2 × ZP 3 & 12.95 & 3.4 & 373.85 & $6.6^{*}$ & 3781.92 & -0.9 \\
ZP 2 × ZP 4 & 12.86 & 2.6 & 355.91 & 1.4 & 3845.26 & 0.8 \\
ZP 2 $\times$ ZP 5 & 12.73 & 1.6 & 348.88 & -0.6 & 4139.47 & $8.5^{* * *}$ \\
\hline
\end{tabular}

$\stackrel{+* * *}{*}$ Significant at the $0.1,0.05$, and 0.1 probability levels, respectively.

pollinated (Table 8), but only ZP 1st $\times$ ZP 5 combination had significant decrease of $6.2 \%(\mathrm{P}<0.1)$. None of the combinations of $\mathrm{ZP} 2$ hybrid had significantly different $\mathrm{GY}$ from $\mathrm{ZP} 2 \times \mathrm{ZP} 2$. However, ZP 2 st $\times \mathrm{ZP} 3$ showed $6.2 \%$ and $\mathrm{ZP} 2 \mathrm{st} \times \mathrm{ZP} 44.7 \%$ higher grain yield than $\mathrm{ZP} 2 \mathrm{ft} \times$ $\mathrm{ZP} 2$. Also, ZP 2st $\times$ ZP 3 had 5.2\% higher TKW than ZP 2 isogenically pollinated $(\mathrm{P}<0.1)$, while none of the $\mathrm{ZP} 1$ hybrid combinations showed significant effect for this trait. There was no significant change in KNM for ZP 1 hybrid, while two Plus-hybrid combinations of ZP 2 showed positive effect on this trait by increase of $4.7 \%$ in $\mathrm{ZP} 2 \mathrm{st} \times$ $\mathrm{ZP} 1(\mathrm{P}<0.1)$ and $8.0 \%$ in $\mathrm{ZP} 2 \mathrm{st} \times \mathrm{ZP} 5(\mathrm{P}<0.01)$.

SSR marker analysis revealed a total of 133 alleles, with 6.3 alleles per loci on average (Table 3 ). The PIC was in the range from 0.239 (umc1841) to 0.873 (bnlg1350), with the average value of 0.723 .

MRD was in the range from 0.211 between $Z P 1$ and $\mathrm{ZP} 4$ to 0.378 between ZP 2 and ZP 5 hybrids (Table 9). ZP 4 was genetically most similar to ZP 1 hybrid, while ZP 1 was the most similar to ZP 2 hybrid. ZP 5 was genetically most distant to both hybrids.

Dendrogram obtained according to MRD clearly separated ZP 5 hybrid, which is loosely attached to the rest of the genotypes (Figure 1). ZP 1 and ZP 4 formed a subcluster with ZP 3 and ZP 2 separately attached to it.

Table 8. Plus-hybrid effect on grain yield (GY), thousand kernel weight (TKW), and kernel number per square meter (KNM).

\begin{tabular}{lccc}
\hline & \multicolumn{3}{c}{ Plus-hybrid effect (\%) } \\
\cline { 2 - 4 } Genotype & GY & TKW & KNM \\
\hline ZP 1st $\times$ ZP 2 & 2.2 & -1.0 & 1.8 \\
ZP 1st $\times$ ZP 3 & -2.4 & 2.4 & -1.0 \\
ZP 1st $\times$ ZP 4 & -2.0 & 1.1 & 0.1 \\
ZP 1st $\times$ ZP 5 & $-6.2 \dagger$ & -1.7 & 1.6 \\
ZP 2st $\times$ ZP 1 & 3.7 & 1.8 & $4.7^{\dagger}$ \\
ZP 2st $\times$ ZP 3 & 6.2 & $5.2^{\dagger}$ & 1.8 \\
ZP 2st $\times$ ZP 4 & 4.7 & 3.6 & 3.5 \\
ZP 2st $\times$ ZP 5 & -0.7 & 2.3 & $8.0^{* *}$ \\
\hline
\end{tabular}

${ }^{\dagger},{ }^{* *}$ Significant at the 0.1 and 0.01 probability levels, respectively.

Table 9. Modified Rogers' distance between hybrids.

\begin{tabular}{llllll}
\hline Hybrid & ZP 1 & ZP 2 & ZP 3 & ZP 4 & ZP 5 \\
\hline ZP 1 & 0 & & & & \\
ZP 2 & 0.245 & 0 & & & \\
ZP 3 & 0.275 & 0.292 & 0 & & \\
ZP 4 & 0.211 & 0.310 & 0.216 & 0 & \\
ZP 5 & 0.373 & 0.378 & 0.303 & 0.292 & 0 \\
\hline
\end{tabular}

\section{DISCUSSION}

\section{Anthesis-silking interval}

Anthesis-silking interval did not exceed more than $4 \mathrm{~d}$ on average for any of the hybrid combinations. This interval was adequate to provide optimal pollination and full kernel set on a female hybrid ear (Westgate et al., 2003). In most of the combinations, the pollinator hybrid was pollinating 1 to $4 \mathrm{~d}$ before the female hybrid was silking. Both sterile and fertile versions of $\mathrm{ZP} 1$ silked before $\mathrm{ZP}$ 2 and ZP 5 pollinated, which is desirable for obtaining the highest kernel set (Kaeser, 2003b; Anderson et al., 2004). On the other hand, when silk is "waiting" for the pollen too long, it can easily get to the pollination by some other undesirable genotype. Although difference between ASI in sterile and fertile versions was noticeable, it was not significant, meaning that CMS did not affect ASI. Kaeser et al. (2003b) obtained same results.

\section{CMS effect on grain yield}

Only one hybrid per se had average GY increase of 0.6 $\mathrm{t} \mathrm{ha}^{-1}(4.9 \%)$. However, this increase was not significant, meaning that the CMS effect on this trait was negligible. The $\mathrm{S}$ type of sterility terminates pollen production in later phases than the other two types (Kaul, 1988). This is probably the reason why our results were not in agreement with the results showing high yield increase in sterile genotypes (Weingartner et al., 2002a; Kaeser et al., 2003a). Munsch (2008) determined both positive and negative CMS effect on GY (from $-8 \%$ to $8 \%$ ) and revealed that the lowest change occurred with hybrids in S type of sterility, which is partly in accordance with our results. Still, the authors showed that these variations were not significantly dependent on the type of male sterile cytoplasm. In addition, Uribelarrea et al. (2002) did not determine positive CMS effect on GY in maize, which was partially explained by the fact that they used modern hybrids that have smaller tassels and higher stress tolerance (Duvick, 2005). This could also be the reason for poor response of hybrids in our research.

The effect of CMS would probably have been stronger if sterile hybrids had been compared to their fertile analogues without detasseling. Regarding this, the effects of pollen not being produced and type of cytoplasm (sterile/fertile) were separated, unlike in some other studies (Uribelarrea et al., 2002; Weingartner et al., 2002a; Kaeser et al., 2003a). Actually, CMS effect was reduced just to the effect of sterile cytoplasm and the difference in mitochondrial DNA between sterile hybrids and their fertile analogue isogenically pollinated. The fact that different CMS types have different effect on maize GY leads us to the conclusion that the effect of sterility refers not only to the gain of pollen not being produced, but also to the impact of cytoplasm and its genes. In accordance with this, the effect of each subtype among the three main types of CMS should be examined. 


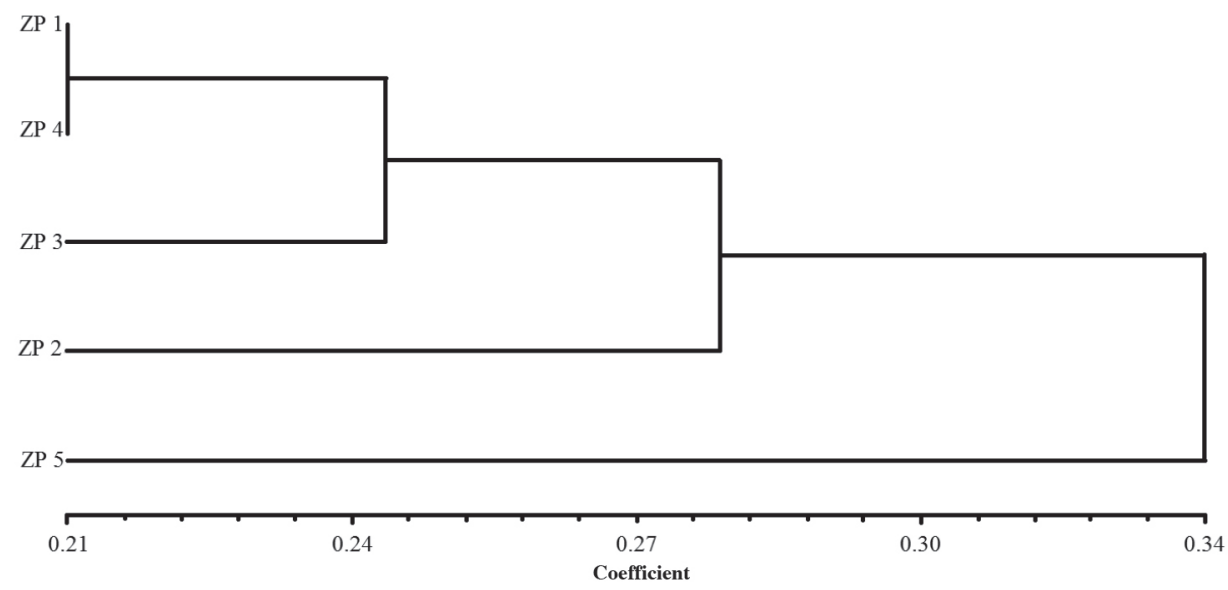

Figure 1. Dendrogram of the hybrids computed based on the modified Rogers' distance.

Considering only ZP 2 hybrid, higher GY was due to higher TKW (4.0\%) and KNM (4.7\%). Some authors determined that higher KNM was responsible for higher grain yield of the sterile hybrids, while TKW did not have significant effect or even was negatively correlated with GY (Weingartner et al., 2002a; Kaeser et al., 2003b). Munsch (2008) obtained similar results (9\% increase in kernel number), except that hybrids in T type of sterility had significant kernel weight decrease of $8 \%$ compared to its fertile analogue.

\section{Xenia effect on grain yield}

Several authors have shown that xenia effect on GY can be highly significant positive (Bulant and Gallais, 1998; Weingartner et al., 2002a; 2002b), but this was not in agreement with the results obtained in this research (effect was from $-5.4 \%$ to $3.4 \%$ ). Some authors also obtained variations in this effect: in the study of Munsch (2008) xenia effect was from $-2 \%$ to $15 \%$, while in Liu et al. (2010) it was from $-16 \%$ to $12 \%$. The year of examination and sterile cytoplasm did not modify xenia effect on this trait in our study, the same as in the study of Weingartner et al. (2002a).

Significant xenia effect on TKW was obtained under the influence of two pollinators. These results are in accordance with those obtained by Bulant and Gallais (1998) and Weingartner et al. (2002a; 2002b). ZP 5 hybrid had significant impact on KNM increase (4.7\% and 8.0\%) in both female hybrids. Weingartner et al. (2002a) also determined that one pollinator increased $\mathrm{KNM}$ of $6 \%$, while Liu et al. (2010) did not obtain KNM increase under xenia effect. The impact of xenia on number of kernels has not been explained so far, but it can be partially explained with good flowering synchronization between female and pollinator hybrids in this study. It is noticeable that significant increase in KNM was obtained when pollinator was ZP 5 hybrid, which was the pollinator flowered the latest. Compared to female hybrids, ZP 5 pollinated $2 \mathrm{~d}$ after ZP 1 and $1 \mathrm{~d}$ before ZP 2 silked, while all the other pollinators shed pollen 1 to $3 \mathrm{~d}$ earlier than ZP 5. This confirms the statements that maximum kernel set is obtained when pollination occurs after silking (Kaeser et al., 2003b; Anderson et al., 2004).

One of the reasons for poor xenia effect on the examined traits could be the way xenia was calculated in our study. Weingartner et al. (2002a) and Munsch (2008) calculated xenia effect as the difference between non-isogenically pollinated sterile hybrid and isogenically pollinated sterile hybrid, which means that they did not separate xenia and CMS effects. The way xenia was calculated in our research is more reliable, because CMS could have modified the effect of xenia on some traits. The other reason for poor response to xenia could be the genetic constitution of the female hybrids. Bulant and Gallais (1998) determined that the average increase in kernel weight was twice weaker when a single cross, instead of an inbred line, was used as a female. Kernel heterozigosity level of three-way cross hybrids is higher, while the inbreeding depression by self fertilization is lower than in single cross hybrids and the response to cross fertilization is less than expected. Both female hybrids in our research were three-way crosses, thus failing to respond stronger to xenia.

\section{Plus-hybrid effect on grain yield}

While Weingartner et al. (2002a) and Munsch (2008) got significantly positive Plus-hybrid effect on GY (9\% and $7 \%$ on average, respectively), this significant positive effect was absent in our study ( $0.7 \%$ on average). ZP 2 hybrid generally had stronger and more positive responses to the effects examined (3.5\% on average) than ZP 1 (-2.1\% on average). This confirms previous findings that genotypes of CMS, as well as pollinator hybrids are determinant for the studied traits (Weingartner et al., 2002a; Munsch, 2008). The same was for TKW and KNM traits, where all Plus-hybrid combinations of ZP 2 showed increased values. Increase of kernel weight and kernel number was also obtained by Weingartner et al. (2002a) and Munsch (2008). 
Xenia effect strongly depends on the genotypes used as a female and as a pollinator (Liu et al., 2010). The same applies to the Plus-hybrid effect. When ZP 1st was used as a female and ZP 2 as a pollinator there was a slight GY increase of $2.2 \%$. Otherwise GY increase of $3.7 \%$ was obtained. When kernel weight is observed, ZP 1 hybrid was better when used as pollinator than as CMS hybrid. This suggests that when selecting hybrids for a Plushybrid mixture, it would be necessary to examine their reaction and choose the right variant, particularly because hybrid pollinator per se is included in the mixture. It is also noticeable that the combined effect of CMS and xenia is not straightforward and easily predicted. It is not a simple cumulative effect of these two factors, but there are a lot of other factors and interactions that influence gain from a Plus-hybrid mixture. Similar conclusions were obtained in the study of Weingartner et al. (2002a).

\section{Relevance of genetic distance between hybrids for Plus-hybrid effect}

Genetic distance estimation based on SSR analysis between hybrids used in this study is in accordance with the data on the origin of hybrids. Also, dendrogram grouped the most similar hybrids into the same clusters. It seems that genetic distance is not relevant for prediction of the degree of xenia effect in the Plus-hybrid system, which is in accordance with results obtained by Munsch (2008). ZP 5 was genetically the most distant hybrid from both female hybrids, but Plus-hybrid combinations with this hybrid for all the traits, except KNM, were the worst. Genetic difference between genotypes in a Plus-hybrid mixture is desirable, but not relevant for the xenia effect, especially if three-way crosses are used. Many factors could influence genetic distance values, such as the number of markers used and distribution of the markers in the genome (Munsch, 2008). In total, 21 markers were used in the study, and according to Souza et al. (2008) 16 markers are enough for genotype analysis. Munsch (2008) analyzed 30 genotypes using 20 SSR markers and revealed 71 alleles, which is much less than the number of alleles obtained in this research. Further, the markers were distributed on nine out of ten maize chromosomes. Most probably, additional markers would not have changed the results of the genetic distance between hybrids.

Data on the relation between the genetic distance of inbred lines and heterosis of $\mathrm{F}_{1}$ generation are contradictory. Betran et al. (2003) and Mladenović Drinić et al. (2012) found positive correlation between genetic distance of inbred lines and resulting heterosis, but some studies showed weak or no correlation (Xu et al., 2004; Kiula et al., 2007).

Since all the hybrids in this study originate from the same seed company a guess is that they have high genetic similarity and therefore heterozigosity level of kernels due to a xenia effect could not be strongly expressed. Maybe interrelation between xenia effect and genetic distance for the hybrids from different seed companies should be examined. However, Munsch (2008) studied relevance of genetic distance for predicting xenia effect using hybrids from seven different seed companies and MRD values were in the range from 0.048 to 0.146 , which is quite less than in our study. This could be a reflection of the common origin of European maize, breeding to maintain large genetic diversity within the gene pool, and probably exchanges of material among breeding companies. It is also known that heterosis expression in kernels of threeway cross hybrids (which were used as females in our research) is weaker than in single crosses or inbred lines (Bulant and Gallais, 1998). The hypothesis that genetic distance between hybrids can be used for the prediction of xenia effect could not be confirmed in our experiment. This effect was more dependent on pollinator ability and female genotype. However, for a definite conclusion, a number of SSR loci examined should be higher with single cross hybrids being used instead of three-way.

\section{CONCLUSIONS}

Cytoplasmic male sterility (CMS) did not show relevant impact on the two studied hybrids, with only one of them having positive but not significant change in grain yield. Xenia showed significant impact on thousand kernel weight of one hybrid and kernel set of both hybrids, but not on the grain yield itself. Plus-hybrid effect on grain yield was not significant and positive as expected. Moreover, one hybrid had negative response for most of the examined traits. We can assume that Plus-hybrid effect would be more positive if sterile hybrids in $\mathrm{C}$ or $\mathrm{T}$ type of sterility were used instead of $\mathrm{S}$ type. In addition, it can be assumed that single crosses are more suitable to be used as female sterile hybrids than threeway crosses. Optimal flowering synchronization between female and pollinator hybrid is of great importance and the highest kernel set can be obtained when pollination occurs after silking. Genetic distances between hybrids were of no relevance for xenia effect in the Plus-hybrid mixture in this study. The reason for this could be genetic constitution of the hybrids or relatively high genetic similarity between the genotypes used. Plus-hybrid effect is not easily predicted as it is not the result of simple cumulative effects of individual CMS and xenia effects. Finally, Plus-hybrids could be worth for commercial maize production, but we would recommend it for genotypes with slightly poorer performance per se that have already been produced on a sterile base rather than for modern hybrids with higher performance. More studies including a greater number of hybrids at multiple locations and years must be performed.

\section{ACKNOWLEDGEMENTS}

This research was supported by the Ministry of Education, Science and Technological Development of the Republic of Serbia, Grant nr TR31068. 


\section{LITERATURE CITED}

Anderson, S.R., M.J. Lauer, J.B. Schoper, and R.M. Shibles. 2004. Pollination timing effects on kernel set and silk receptivity in four maize hybrids. Crop Science 44:464-473.

Betran, F.J., J.M. Ribaut, D. Beck, and D.G. de Leon. 2003. Genetic diversity, specific combining ability, and heterosis in tropical maize under stress and nonstress environments. Crop Science 43:797-806.

Bulant, C., and A. Gallais. 1998. Xenia effects in maize with normal endosperm: I. Importance and stability. Crop Science 38:1517-1525.

Bulant, C., A. Gallais, E. Matthys-Rochon, and J.L. Prioul. 2000. Xenia effects in maize with normal endosperm: II. Kernel growth and enzyme activities during grain filling. Crop Science 40:182-189.

Duvick, D.N. 2005. Genetic progress in yield of United States maize (Zea mays L.) Maydica 50:193-202.

Havey, M. 2004. The use of cytoplasmic male sterility for hybrid seed production. p. 623-634. In Daniell, H. and C.D. Chase (eds.) Molecular Biology and Biotechnology of Plant Organelles. Springer-Verlag, Berlin, Germany.

Kaeser, O., S. Chowchong, and P. Stamp. 2003b. Influence of silk age on grain yield and yield components of normal and malesterile maize (Zea mays L.) Maydica 48:171-176.

Kaeser, O., U. Weingartner, K.-H. Camp, S. Chowchong, and P. Stamp. 2003a. Impact of different CMS types on grain yield of dent $\mathrm{x}$ flint hybrids of maize (Zea mays L.) Maydica 48:15-20.

Kaul, M.L.H. 1988. Male sterility in higher plants. Springer-Verlag, Berlin, Germany.

Kiula, B.A., N.G. Lyimo, and A.M. Botha. 2007. Association between AFLP-based genetic distance and hybrid performance in tropical maize. Plant Breeding 127:140-144.

Laughnan, J.R. and S. Gabay-Laughnan. 1983. Cytoplasmic male sterility in maize. Annual Review of Genetics 17:27-48.

Liu, Y.-E., P. Liu, S.T. Dong, and J.-W. Zhang. 2010. Hormonal changes caused by the xenia effect during grain filling of normal corn and high-oil corn crosses. Crop Science 50:215-221.

Lynch, M. and J.B. Walsh. 1998. Genetics and analysis of quantitative traits. Sinauer Associates, Inc., Sunderland, Massachusetts, USA.

Mladenović Drinić, S., M. Kostadinović, D. Ristić, M. Stevanović, Z. Čamdžija, M. Filipović, et al. 2012. Correlation of yield and heterosis of maize hybrids and their parental lines with genetic distance based on SSR markers. Genetika 44:399-408.
Munsch, M. 2008. Yield potential of modern European plus-hybrids and relevance of genetic diversity for xenia in maize (Zea mays L.) $\mathrm{PhD}$ thesis. Federal Institute of Technology, Agronomy and Plant Breeding, Zurich, Switzerland.

Reif, J.C., A.E. Melchinger, and M. Frisch. 2005. Genetical and mathematical properties of similarity and dissimilarity coefficients applied in plant breeding and seed bank management. Crop Science 41:1-7.

Rohlf, F.J. 2000. Numerical taxonomy and multivariate analysis system, v 2.11a. Exeter Software, East Setauket, New York, USA.

Sofi, P.A., A.G. Rather, and S.A. Wani. 2007. Genetic and molecular basis of cytoplasmic male sterility in maize. Communications in Biometry and Crop Science 2(1):49-60.

Souza, S., V. Carpentieri-Pipolo, C. Ruas, V. Carvalho, P. Ruas, and A. Gerage. 2008. Comparative analysis of genetic diversity among the maize inbred lines obtained by RAPD and SSR markers. Brazilian Archives of Biology and Technology 51:183-192.

Thomison, P.R., A.B. Geyer, L.D. Lotz, H.J. Siegrist, and T.L. Dobbels. 2002. TopCross High-Oil corn production: Agronomic performance. Agronomy Journal 94:290-299.

Thomison, P.R., A.B. Geyer, L.D. Lotz, H.J. Siegrist, and T.L. Dobbels. 2003. Top-cross high oil corn production: select grain quality attributes. Agronomy Journal 95:147-154.

Uribelarrea, M., J. Cárcova, M.E. Otegui, and M.E. Westgate. 2002. Pollen production, pollination dynamics, and kernel set in maize. Crop Science 42:1910-1918.

Weingartner, U., K.-H. Camp, and P. Stamp. 2004. Impact of male sterility and xenia on grain quality traits of maize. European Journal of Agronomy 21:239-247.

Weingartner, U., O. Käser, M. Long, and P. Stamp. 2002a. Combining cytoplasmic male sterility and xenia increases grain yield of maize hybrids. Crop Science 42:1848-1856.

Weingartner, U., T.J. Prest, K.-H. Camp, and P. Stamp. 2002b. The plus-hybrid system: a method to increase grain yield by combined cytoplasmic male sterility and xenia. Maydica 47:127-134.

Westgate, M.E., J. Lizaso, and W. Batchelor. 2003. Quantitative relationships between pollen shed density and grain yield in maize. Crop Science 43:934-942.

Williams, J., J. Hanafey, A. Rafalski, and S. Tingey. 1993. Genetic analysis using random amplified polymorphic DNA markers. Methods in Enzymology 218:704-740.

Wright, S. 1978. Evolution and genetics of populations. Vol. IV. The University of Chicago Press, Chicago, Illinois, USA.

Xu, S.-X., J.I.E. Liu, and G.-S. Liu. 2004. The use of SSRs for predicting the hybrid yield and yield heterosis in 15 key inbred lines of Chinese maize. Hereditas 141:207-215. 